\title{
Editorial
}

\section{Kyasanur forest disease: a rare viral hemorrhagic disease in India}

\author{
Rohit Dhaka $^{1}$, Ramesh Verma ${ }^{1}$, Raj Kumar', Mukesh Dhankar ${ }^{2}$, \\ Kapil Bhalla $^{3}$, Ginni Agrawal ${ }^{1}$
}

\author{
${ }^{1}$ Department of Community Medicine, Pt B D Sharma PGIMS, Rohtak (Haryana) India \\ Department of Pediatric, ${ }^{2}$ LHMC, New Delhi, ${ }^{3}$ Pt B D Sharma PGIMS, Rohtak, Haryana, India \\ *Correspondence: \\ Dr. Ramesh Verma, \\ E-mail: drrameshverma69@gmail.com
}

Copyright: $@$ the author(s), publisher and licensee Medip Academy. This is an open-access article distributed under the terms of the Creative Commons Attribution Non-Commercial License, which permits unrestricted non-commercial use, distribution, and reproduction in any medium, provided the original work is properly cited.

Kyasanur Forest Disease (KFD) is a rare hemorrhagic disease in India. KFD was isolated from sick and dying monkeys in the Kyasanur Forest of the Shimoga district, Karnataka State in India in 1957. ${ }^{1,2}$ Shimoga district is located at 571 metres altitude, between $13^{0} 27^{\prime}$ and $14^{0} 39^{\prime}$ north longitude, and between $74^{0} 38^{\prime}$ and $76^{\circ} 4^{\prime}$ latitude. The Shimoga district of Karnataka state is full of closed forests and few open forests. Shimoga has 276855 hectares of forest land. The initial focus of about $100 \mathrm{sq}$ $\mathrm{km}$ in Sagar Taulka, Shimoga district, later on the disease has been widened and recorded from Uttar Kannada, Udipi, Mangalore and Chikmagalore districts of Karnataka state. KFD is caused by a highly pathogenic KFD virus (KFDV), belongs to family Flaviviridae. $\mathrm{KFDV}$ is a spherical, enveloped virus of $45 \mathrm{~nm}$ in diameter and has a single-stranded, positive-sense RNA genome. $^{3}$

KFD is a zoonotic disease and endemic in southern part of India. Genetic analysis of 48 viruses isolated in India during 1957-2006 showed low diversity i.e. 1.2\%. KFDV commonly infects the black faced langur monkey (Semnopithecus entellus), red faced monkey (Macaca radiate), Rattus blanfordi, Rattus rattus wroughtoni (rat), Suncus murinus (shrew) and a bat Rhinolophus rouxi. KFDV has been isolated from 16 species of ticks and it is transmitted by the bite of infective ticks (Haemaphysalis spinigera), especially nymphal stage, that's remain infectious throughout their lives. No evidence for humanto-human transmission. ${ }^{4}$ Large domestic animals (cows, goats, sheep) that become infected are thought be important only for sustaining tick population. Also, lactating monkeys are believed to shed minute quantities of the virus in their milk. In enzootic state, KFDV circulates through small mammals such as rodents, shrews, ground birds and as array of tick species including $H$. spinigera. When monkeys come in contact with the infected ticks, they get infected, amplify and disseminate the infection creating hot spots of infection. The people who pass through the forest are bitten by the infected nymphs of $H$. spinigera, which are highly anthropophilic. KFDV also circulates in small animals such as rodents, shrews and birds. ${ }^{5}$

Local villagers staying in and around the forest area frequently visit the forest for collection of fire woods, grass and get infected through tick bites. Generally women mostly visit the forest for fire wood collection, whereas children do not. Men are in between. So, women have the highest opportunity to get infected whereas children have the lowest. The incubation period is 3-8 days and patients presented with following symptoms like chills, frontal headache, bodyache, and high fever for 5-12 days. Ticks have a definite-stage wise seasonal activity. The adults become active after a few monsoon rains in June. The adult population reaches its peak during July and August and gradually decline in September. Each fed female lays large number of eggs. Larvae preferably feed on small animals like rodents and shrews etc. Larval population builds up in the monsoon months but remains dormant under the forest litter and becomes suddenly active when the litter dries up during the past monsoon month October to December. Nymphal activity is high from January to May. Epidemics coincide with nymphal activity, hence nymphs are considered as the most important stage for human transmission. Adult ticks feed on large animals like cattle and monkey etc. these large animals are good hosts for proliferation of ticks but are not significant for virus transmission due to insignificant viremia in them.

The rainy season lasts from June to September, but the rainfall varies greatly from one year to another, with a mean of 85 inches per year. The humid and relatively 
fertile bottoms between the terrain's undulations are adequate for the cultivation of paddy fields. High humidity generated from the cultivated fields is suitable for maintenance of the ticks throughout the year and availability of nearby forest sustains a large population of wild moneys. Such ecological specificity is rarely seen in any other parts of India. All these in combination may be responsible for the geographical localization of KFDV only to Karnataka state of India.

The initial prodromal stage is brought on by a sudden onset of fever and severe headache, hypotension and hepatomegaly, sore throat, diarrhoea and vomiting, anorexia, insomnia, severe pain in the lower and upper extremities, and prostration. ${ }^{6,7}$ Bradycardia and inflammation of the conjunctiva are also commonly observed, along with acute lymphopenia and eosinopenia which can occur within the first or second week of infection. The next stage is characterized by haemorrhagic complications such as intermittent epistaxis, hematemesis, melena, and frank blood in stool; neurological manifestations such as mental confusion, tremors, and abnormal reflexes; and bronchopneumonia or development of coma which may occur in some cases prior to death. ${ }^{8}$ A stage of recovery may be observed next, followed by a last stage of fever in certain cases. Other pathologic manifestations of KFD in human patients include parenchymal degeneration of the liver and kidney, haemorrhagic pneumonitis, and a moderate to marked prominence of the reticuloendothelial elements in the liver and spleen with marked erythrophagocytosis. ${ }^{9}$

Mild meningoencephalitis may occur amongst a small portion of patients, developing coma or bronchopneumonia prior to death. IgE has also been implicated as a cofactor in the immunopathology of KFD and possibly of other haemorrhagic fevers. ${ }^{10}$ The exact cause of haemorrhage is not known although disseminated intravascular coagulation is suspected. There were 466 human cases during initial outbreak and 181 more the following year and has caused epidemic outbreaks of haemorrhagic fever affecting 400 to 1000 people per year since then, with mortality rate of 4 and $15 \% .^{11}$ In 2012,9 persons were found positive for KFD, in Theerthahlli taluk of district Karnataka. $^{12}$

The exact nature of spread of KFDV and its origin are not certain. One school of thought is that the virus might have got introduced to India via migrant birds. If so, why KFDV thereafter stopped being introduced into India by migrant birds or was not carried to other parts of India remains a question. Sudden appearance of KFDV in 1957 might be due to the first introduction by migrant birds. The virus did not spread to other parts of the country and got adapted to the regional environmental/ecological conditions. Another possibility is that KFDV might have been introduced to India a long time ago through the slave trade and silently perpetuated in the subcontinent, resulting in an epidemic only in the year 1957, when it was first identified and reported. In any event, the possibility remains that KFD was present before

1957 without being recognized or reported. Syndromic approach is used to diagnose KFD while the laboratory tests include hemagglutination inhibition, immunofluorscence and neutralization tests. Neutralization test is more useful to diagnose KFD.

\section{Treatment and prevention ${ }^{13}$}

There is no specific treatment for KFD but a timely supportive therapy reduces the mortality in human being. One or two treatments of forest floor with the insecticide Lindane was highly effective in killing ticks. This was particularly useful to clear infection following the detection monkey death. Tick repellents such as N,NDiethyl-meta-toluamide (DEET), Dimethyl-phosphorothidate (DMP), Dibutyl phthalate (DBP) provide 90$100 \%$ protection against tick bite. Vaccination to the villagers and forest workers is effective. In India, National institute of Virology (NIV) has developed an inactivated chick embryo tissue culture vaccine. This vaccine stimulates neutralizing antibodies in about $70 \%$ of the case. Two doses of vaccination are requires at an interval of 4 weeks with a booster dose after every year and administered subcutaneously with a dose of $1.0 \mathrm{ml}$ ( $0.5 \mathrm{ml}$ below age 6$)$.

\section{REFERENCES}

1. Work TH, Trapido H. Kyasanur Forest disease, a new virus disease in India. Indian $\mathrm{J}$ Med Sci. 1997; 11:341.

2. Gould E, Solomon T. Pathogenic flaviviruses. The Lancet. 2008;371(9611):500-9.

3. Pattnaik P. Kyasanur forest disease: An epidemiological view in India. Rev Med Virol. 2006; 16 (3):151-65.

4. Borio L, Inglesby T, Peters CJ, Schmaljohn AL, Hughes JM, Jahrling, et al. Hemorrhagic fever viruses as biological weapons: Medical and public health management. J American Med Association 2002;287(18):2391-405.

5. Burke DS, Monath TP. Flaviviruses. In: Knipe DM, Howley PM, eds. Fields Virology. Philadelphia, PA: Lippencott-Raven; 2001: 1046-1109.

6. Brown RN, Lane RS, Dennis DT. Geographic Distributions of Tick-Borne Diseases and Their Vectors. In Goodman JL, Dennis DT, Sonenshine DE, eds. Tick-Borne Diseases of Human. Washington, DC: ASM press; 2005: 363-391.

7. Roy P, Maiti D, Goel MK, Rasania SK. Kyasanur Forest Disease: An emerging tropical disease in India. J Res Med Den Sci. 2014;2(2):1-4.

8. Adhikari Prabha MR, Prabhu MG, Raghuveer CV, Bai M, Mala MA. Clinical study of 100 cases of Kyasanur Forest disease with clinicopathological correlation. Indian J Med Sci. 1993;47(5):124-30. 
9. Iyer CG, Laxmana Rao R, Work TH, Narasimha Murthy DP. Kyasanur Forest Disease VI. Pathological findings in three fatal human cases of Kyasanur Forest Disease. Indian J Med Sci. 1959;13:1011-22.

10. Pavri K. Clinical, clinicopathologic, and hematologic features of Kyasanur Forest disease. Rev Infect Dis. 1989;11(4):S854-S59.

11. Gould E, Solomon T. Pathogenic flaviviruses. The Lancet. 2008;371(9611):500-9.

12. Kyasanur Forest disease in Karnataka region of India. 2012. Available at: http://ibnlive.in.com/ generalnewsfeed/news/nine-positive-cases-of-kfd- disease-detected/961531.html. Accessed on 3 November 2017.

13. Institute of tropical medicine Antwerp. Kyasanur Forest Disease. Available at: http://itg.contente eu /Generated/pubx/161/arboviruses/kyasanur_ forest_disease.htm. Accessed on 3 November 2017.

Cite this article as: Dhaka R, Verma R, Kumar R, Dhankar M, Bhallla K, Agrawal G. Kyasanur forest disease: a rare viral hemorrhagic disease in India. Int J Community Med Public Health 2018;5:3149-51. 